\title{
The axillary flap in oncoplastic resection of breast cancers located in the upper-outer quadrants: a new surgical technique
}

\author{
Daniele Bordoni ${ }^{1}$, Pierfrancesco Cadenelli ${ }^{2}$, Matteo Ornelli ${ }^{3}$, Giuseppe Falco ${ }^{4}$, Antonello Accurso ${ }^{5}$, Antonio Gloria ${ }^{6}$, \\ Saverio Maietta ${ }^{7}$, Nicola Rocco ${ }^{*^{*}}$ (D) and Cesare Magalotti ${ }^{1}$
}

\begin{abstract}
Background: The combination of breast conserving surgery (BCS) with plastic surgery techniques has provided a useful surgical tool matching the radicality of the oncological excision with the preservation of breast cosmesis. Even though BCS represents a good option for surgical treatment of tumors located in these quadrants, wide excisions often necessitate breast reshaping in order to avoid nipple areola complex (NAC) displacement and skin retraction. We present a new surgical technique to repair upper-outer quadrants' defects following breast cancer excision using dermo-glandular flaps and an axillary adipo-fascial flap.

Methods: During the period from January 2014 to December 2015, 168 patients with an upper-outer quadrant's breast cancer have been treated in our Department. 83 women have been treated with the described oncoplastic technique and immediate contra-lateral symmetrisation and 85 women underwent standard BCS. We present surgical, oncological and cosmetic outcomes comparing our results with standard BCS.

Results: At a mean follow-up of 27 months loco-regional recurrences in the two groups were comparable. Shortterm complication rates were comparable between the two groups. Re-intervention rates for positive margins were significantly higher in the standard BCS group. The overall satisfaction with cosmetic outcome both assessed by the patient and the surgeon was significantly higher in the oncoplastic group.

Conclusions: The proposed oncoplastic technique represents a safe and effective solution for reshaping that follows upper-outer breast cancer wide excision, achieving comparable complication rates, lower re-intervention rates for positive margins and better cosmetic results when compared with standard BCS.
\end{abstract}

Keywords: Oncoplastic breast surgery, Breast Cancer, Surgical technique

\section{Background}

The upper-outer quadrant of the breast is the most common location for breast cancer. Conventional Breast Conserving Surgery (BCS) is nowadays the standard surgical approach for the treatment of breast cancer located in the upper outer quadrants.

Although BCS followed by radiotherapy presents comparable survival rates with patients treated with mastectomy, it may hesitate in breast deformity in $20-30 \%$ of cases $[1,2]$. Furthermore large series of patients treated by

\footnotetext{
* Correspondence: nicolarocco2003@gmail.com

${ }^{8}$ Department of Clinical Medicine and Surgery, University of Naples "Federico

II", Via S.Pansini, 5, 80131 Naples, Italy

Full list of author information is available at the end of the article
}

BCS show 20 to $40 \%$ of involved margins necessitating additional surgery to achieve oncological radicality $[3,4]$.

The possible distortion of breast shape and the following poor cosmetic result lead surgeons to develop different surgical techniques in order to overcome the aestethic discomfort for the patient [5]. The so-called oncoplastic breast surgery allows both a better cosmetic result and a wider tumor resection decreasing the risk of re-operation for positive margins [6-8]. Glandular resections regarding less then $20 \%$ of breast volume at the level of the upper-outer quadrants are usually well tolerated and do not hesitate in breast deformity. Even though BCS represents a good option for surgical treatment of tumors located in these quadrants, wide excisions often

(c) The Author(s). 2019 Open Access This article is distributed under the terms of the Creative Commons Attribution 4.0 International License (http://creativecommons.org/licenses/by/4.0/), which permits unrestricted use, distribution, and reproduction in any medium, provided you give appropriate credit to the original author(s) and the source, provide a link to the Creative Commons license, and indicate if changes were made. The Creative Commons Public Domain Dedication waiver (http://creativecommons.org/publicdomain/zero/1.0/) applies to the data made available in this article, unless otherwise stated. 
necessitate breast reshaping in order to avoid nipple areola complex (NAC) displacement and skin retraction. Effective methods such as the raquet mammoplasty, modifications of the Wise pattern for skin reduction and glandular displacement procedures have been proposed during the years with the aim of improving aesthetic outcomes after BCS [9-11].

We present a new surgical technique to repair upper-outer quadrants' defects following breast cancer excision using dermo-glandular flaps and an axillary adipo-fascial flap. We present surgical and oncological outcomes comparing our results with standard BCS for the treatment of breast cancer located in the upper-outer quadrants.

\section{Methods}

We retrospectively collected from our database all the women who underwent upper-outer quandrantectomies in our Department in the period from January 2014 to December 2015.

Women with a diagnosis of both invasive or in situ breast cancer, affected by both unifocal or multifocal lesions located at the level of the upper-outer quadrant have been enrolled in the study.

We divided our cohort of patients in two groups according with the surgical technique used to excise the breast cancer. The first group included 83 women who underwent our innovative oncoplastic technique and immediate contra-lateral breast symmeytrisation. The second group included 85 women who underwent a standard upper-outer BCS.

Women who previously underwent breast or axillary surgery or chest radiotherapy have been excluded. Patients with clinical pre-operative or histological intra-operative evidence of axillary lymph node involvement have been excluded as well, such as patients presenting skin involvement of the cancer, local recurrence, distant metastases or genetic mutations.

This study was approved by our institutional review board (Santa Maria della Misericordia Hospital Ethical Commitee \# 2014/8769) and appropriate informed consent was obtained from all patients for the surgical procedures performed in the present study and for personal images use and publication.

Ultrasound examination, mammography, MRI and subsequent vacuum-assisted breast biopsy have been performed for all patients. All patients underwent a multidisciplinary approach, involving medical and surgical oncologists, plastic surgeons, breast radiologists, and radiation oncologists. In order to perform breast conserving surgery, we localized the lesions the day before surgery using Tc99m-MAA (Technetium $99 \mathrm{~m}$ macro albumin aggregated); the sentinel lymph node was localized preoperatively by injecting Tc $99 \mathrm{~m}$-nanocoll.
Positive margins were defined as presence of cancer cells at less than $1 \mathrm{~mm}$ from the specimen's margin.

Post-operative radiotherapy (50 Gy on the breast) was administered in each case.

We assessed short-term post-operative complications (occurring less than 30 days after surgery), re-operations for positive margins of resection, local recurrences and cosmetic outcome (both patient-reported and surgeonreported).

\section{Surgical technique}

In the study group patients were marked the day before surgery with a vertical or inverted-T Wise pattern approach according to the balance between the expected tumor excision dimension and breast volume.

Antibiotic prophylactic therapy was administered to all patients according to hospital protocols.

The patient was placed in supine position with the arms abducted to 90 degrees and fixed on arm boards.

A two team approach was always planned in order to reduce operation room time and decrease the surgical stress for patients.

With a blade number 10 the incision was performed and all the skin within the preoperative markings was removed. Subsequently the skin over the tumor was undermined leaving a flap thickness of 3-4 mm. A wide tumor resection through the glandular tissue reaching the pectoralis major muscle fascia was performed.

Intra-operative frozen sections or radiographic examinations (when a cluster of microcalcifications was documented) of the specimen were performed in order to proceed to immediate re-excision if necessary.

Surgical clips were placed in the tumor bed following the tumor resection.

The sentinel lymph node biopsy was performed through the same skin incision.

Subsequent total skin undermining was performed in the medial and inferior quadrants of the breast to completely detach the gland from the skin.

An infero-lateral glandular flap was advanced upward, rotated and fixed with a $2 / 0$ absorbable monofilament suture to an adipo-fascial flap mobilized from the axilla.

Then the residual glandular tissue of the upper portion of the breast could be approximated to the described flap and the nipple-areola complex was fixed in the desired position (Figs. 1 and 2).

When necessary, suction drains were positioned and then the suture was completed.

Contra-lateral symmetrization mammoplasty was always performed simultaneously. 


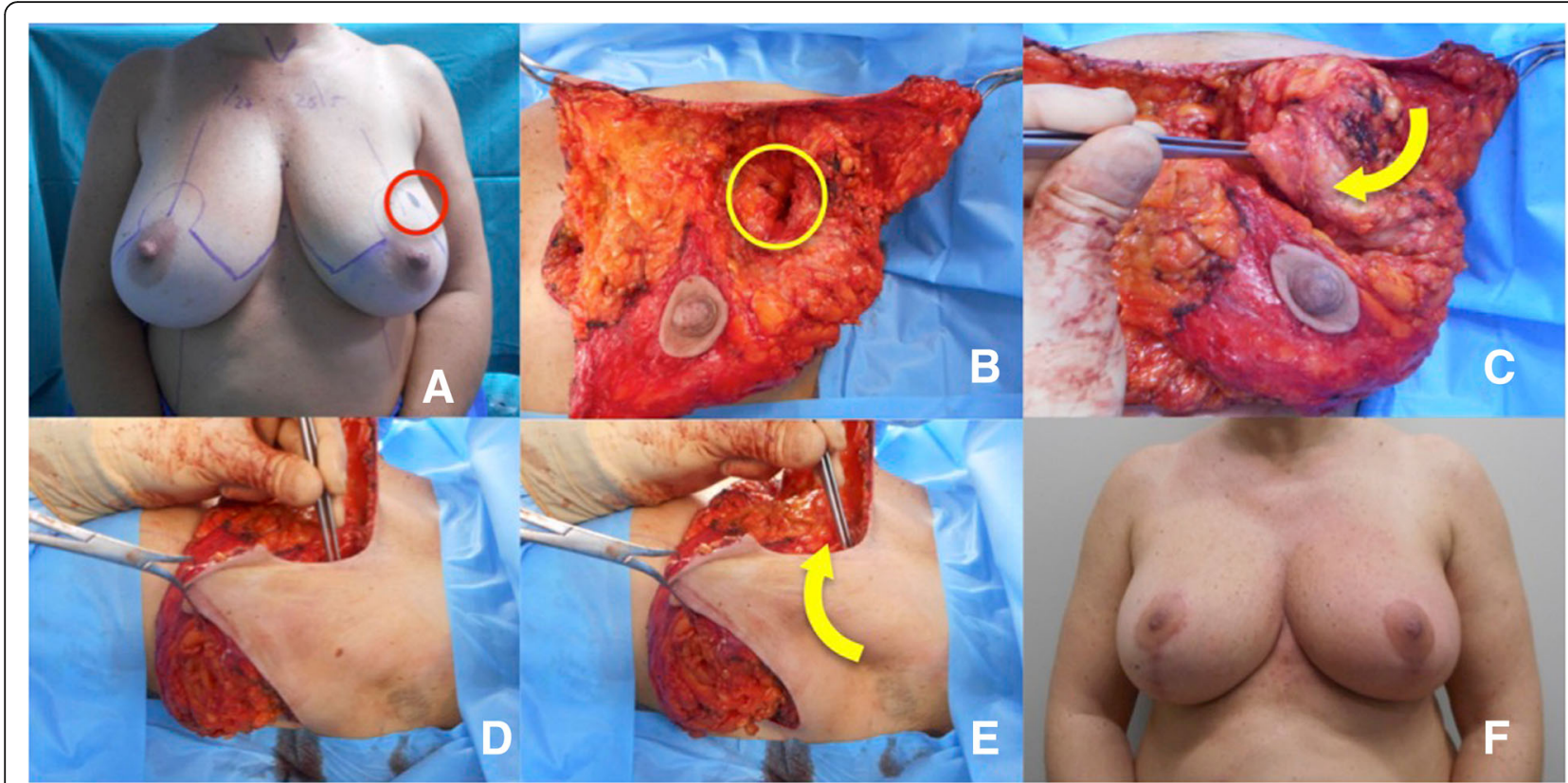

Fig. 1 Case 1. $\mathbf{a}=$ Pre-operative drawings; $\mathbf{b}=$ Intra-operative view: the skin overlying the tumour is undermined in a mastectomy fashion (3-4 $\mathrm{mm}$ flap thickness) and a wide excision of the tumour down to the pectoralis fascia is performed (yellow circle); $\mathbf{c}, \mathbf{d}, \mathbf{e}=$ Intra-operative view: the axillary flap is rotated to fill the defect in the Upper-Outer Quadrant (yellow arrows); $\mathbf{f}=1$-year follow-up result

Antibiotic therapy had been administered to all patients until drain's removal.

In the control group patients underwent a standard upper-outer quadrantectomy. Sentinel Lymph node biopsy was performed through the same surgical incision.

\section{Statistical analysis}

Variables were analysed using the chi-square test. A $p$ value of 0.05 or less was considered statistically significant. All the analyses were performed using SPSS 22 software package (SPSS, Inc., Chicago, IL).

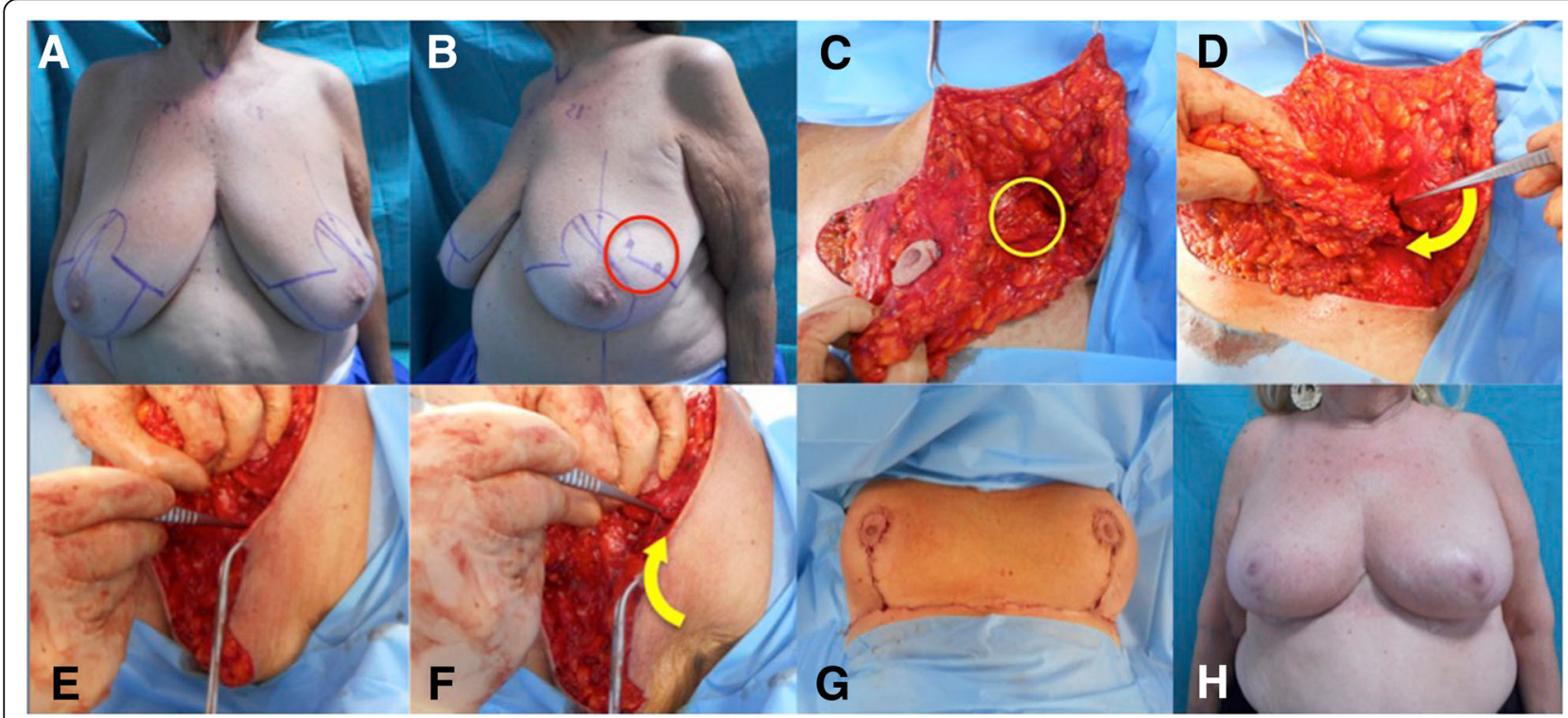

Fig. 2 Case 2. $\mathbf{a}, \mathbf{b}=$ Pre-operative drawings; $\mathbf{c}=$ Intra-operative view: the skin overlying the tumour is undermined in a mastectomy fashion (3-4 $\mathrm{mm}$ flap thickness) and a wide excision of the tumour down to the pectoralis fascia is performed (yellow circle); $\mathbf{d}, \mathbf{e}, \mathbf{f}=$ Intra-operative view: the axillary flap is rotated to fill the defect in the Upper-Outer Quadrant (yellow arrows); $\mathbf{g}=$ Immediate post-operative result; $\mathbf{h}=1$-year followup result 


\section{Results}

During the period from January 2014 to December 2015, 168 patients with an upper-outer quadrant's breast cancer have been treated in our Department.

Eighty-three women have been treated with the described oncoplastic technique and immediate contra-lateral symmetrisation (study group) and 85 women underwent standard BCS (control group).

Patients' Median age was 57.5 years (range 39-76) for the study group and 58.3 years (range 38-79) for the control group, median Body Mass Index (BMI) was 24.5 $\mathrm{kg} / \mathrm{cm} 2$ (range 20.2-32.6) for the study group and 25.1 $\mathrm{kg} / \mathrm{cm} 2$ (range 20.5-33.1) for the control group. The two groups were comparable for baseline characteristics and comorbidities. Patients' comorbidities are presented in Table 1.

Surgical margins of resection were positive in 2 cases (2.4\%) in the study group and in 9 cases $(10.6 \%)$ in the control group $(p=0.03)$. All patients with positive surgical margins have been re-operated in both groups.

Mean time of follow-up was 27 months (range 16-39). During this period one patient (1.2\%) has been re-operated for a local recurrence both in the study group and in the control group. Both patients presenting with a local recurrence were affected by Intermediate Grade (G2) Ductal Carcinoma In Situ (DCIS), completely excised at primary surgery with more than $5 \mathrm{~mm}$ free margin, and recurred as pT1N0 Invasive Ductal Carcinoma (IDC) at a follow-up of 25 months (in the study group) and 20 months (in the control group). Both patients underwent skin sparing mastectomy and breast reconstruction with tissue expander positioning.

All patients included in the study received post-operative radiotherapy. Adjuvant chemotherapy was administered to 23 patients $(27.7 \%)$ in the study group and 26 patients $(30.6 \%)$ in the control group $(p=0.79)$; hormonal therapy was provided to 57 patients $(68.7 \%)$ in the study group and 60 patients $(70.6 \%)$ in the control group ( $p=0.68$ ); Trastuzumab was provided to 13 patients $(15.7 \%)$ in the study group and 14 patients (16.5\%) in the control group. Oncological characteristics ( $\mathrm{T}$ stage,

Table 1 Patients' comorbidities

\begin{tabular}{llll}
\hline Comorbidities & $\begin{array}{l}\text { OBS (83 patients) } \\
\text { N of Patients (\%) }\end{array}$ & $\begin{array}{l}\text { sBCS (85 patients) } \\
\text { N of Patients (\%) }\end{array}$ & $p^{*}$ \\
\hline Tobacco users & $20(24.1 \%)$ & $13(15.3 \%)$ & 0.15 \\
Diabetes & $2(2.4 \%)$ & $5(5.9 \%)$ & 0.26 \\
Obesity & $2(2.4 \%)$ & $3(3.5 \%)$ & 0.67 \\
Overweight & $10(12 \%)$ & $12(14.1 \%)$ & 0.69 \\
Hypertension & $19(22.9 \%)$ & $23(27.1 \%)$ & 0.53 \\
Dyslipidemia & $8(9.6 \%)$ & $6(7.1 \%)$ & 0.56 \\
Coronary Artery Disease & $8(9.6 \%)$ & $8(9.4 \%)$ & 0.96 \\
\hline
\end{tabular}

Grading, ER, PgR, Ki-67 and Her-2) of both groups were comparable and are presented in Table 2.

We experienced a total of 18 (21.7\%) short-term post-operative complications in the study group and 15 $(17.6 \%)$ in the control group $(p=0.50)$. In the study group we experienced 4 wound dehiscences, 4 fat or glandular necrosis, 2 seroma formation, 2 hematoma, 4 marginal skin necrosis, 2 partial NAC necrosis.

In the control group we experienced 3 wound dehiscences, 3 fat or glandular necrosis, 3 seroma formation, 3 hematoma, 2 marginal skin necrosis, 1 partial NAC necrosis. Complication rates were comparable: wound dehiscence $(p=0.67)$, fat or glandular necrosis $(\mathrm{p}=0.67)$, seroma formation $(\mathrm{p}=0.67)$, hematoma $(\mathrm{p}=0.67)$, marginal skin necrosis $(p=0.38)$, partial NAC necrosis $(p=0.56)$.

All complications in both groups have been managed conservatively with ultrasound-guided drainage of hematomas seromas and fat/glandular necrosis, use of hydrogel dressings for wound dehiscences and debridement and hydrogel dressings for minor skin and NAC necrosis.

The cosmetic outcome has been assessed by patients and surgeons following radiotherapy. The overall satisfaction with cosmetic outcome assessed by the patient was considered excellent in 45 cases $(54.2 \%)$ in the study group, while in 32 cases $(36.6 \%)$ in the control group $(p=0.02)$; the overall satisfaction with cosmetic outcome assessed by the surgeon was considered excellent in 48 cases $(57.8 \%)$ in the study group and in 35 cases $(41.2 \%)$ in the control group $(p<0.0001)$ (Table 3).

Table 2 Oncological characteristics

\begin{tabular}{llll}
\hline Oncological Characteirstics & $\begin{array}{l}\text { OBS (83 patients) } \\
\text { N of Patients (\%) }\end{array}$ & $\begin{array}{l}\text { sBCS (85 patients) } \\
\text { N of Patients (\%) }\end{array}$ & $p^{*}$ \\
\hline T & & & \\
Tis & $9(10.8 \%)$ & $3(3.5 \%)$ & 0.07 \\
T1a & $11(13.2 \%)$ & $9(10.6 \%)$ & 0.60 \\
T1b & $16(19.3 \%)$ & $18(21.2 \%)$ & 0.76 \\
T1c & $38(45.9 \%)$ & $40(47.1 \%)$ & 0.88 \\
T2 & $9(10.8 \%)$ & $15(17.6 \%)$ & 0.21 \\
GRADE & & & \\
G1 & $18(21.7 \%)$ & $15(17.6 \%)$ & 0.50 \\
G2 & $35(42.2 \%)$ & $32(37.6 \%)$ & 0.54 \\
G3 & $30(36.1 \%)$ & $28(32.9 \%)$ & 0.66 \\
ER positive & $57(68.7 \%)$ & $52(61.2 \%)$ & 0.31 \\
PgR positive & $55(66.3 \%)$ & $54(63.5 \%)$ & 0.70 \\
Ki-67 > 30\% & $44(53 \%)$ & $39(45.9 \%)$ & 0.36 \\
Her-2 positive & $13(15.7 \%)$ & $14(16.5 \%)$ & 0.89 \\
\hline
\end{tabular}


Table $\mathbf{3}$ Cosmetic outcome assessment

\begin{tabular}{|c|c|c|c|c|c|c|c|c|}
\hline \multirow[t]{2}{*}{ Cosmetic outcome } & \multicolumn{4}{|c|}{ Self assessed } & \multicolumn{4}{|c|}{ Assessed by surgeon } \\
\hline & Excellent & Good & Fair & Poor & Excellent & Good & Fair & Poor \\
\hline \multicolumn{9}{|c|}{ Oncoplastic Breast Surgery $(N=83)$} \\
\hline Breast symmetry & $25(30.1 \%)$ & $48(57.8 \%)$ & $10(12.1 \%)$ & 0 & $35(42.2 \%)$ & $42(50.6 \%)$ & $6(7.2 \%)$ & 0 \\
\hline Nac symmetry & $32(38.6 \%)$ & 49 (59\%) & $2(2.4 \%)$ & 0 & $40(48.2 \%)$ & $38(45.8 \%)$ & $5(6 \%)$ & 0 \\
\hline Breast shape & $39(47 \%)$ & $42(50.6 \%)$ & $2(2.4 \%)$ & 0 & $40(48.2 \%)$ & $39(47 \%)$ & $4(4.8 \%)$ & 0 \\
\hline Scarring & $25(30.1 \%)$ & $35(42.2 \%)$ & $21(25.3 \%)$ & $2(2.4 \%)$ & $28(33.7 \%)$ & $30(36.1 \%)$ & $23(27.7 \%)$ & $2(2.4 \%)$ \\
\hline Overall satisfaction & $45(54.2 \%)$ & $30(36.1 \%)$ & $8(9.6 \%)$ & 0 & $48(57.8 \%)$ & $30(36.1 \%)$ & $5(6 \%)$ & 0 \\
\hline \multicolumn{9}{|c|}{ Standard Breast Conserving Surgery $(\mathrm{N}=85)$} \\
\hline Breast symmetry & $10(11.7 \%)$ & $25(29.4 \%)$ & $41(48.2 \%)$ & $9(10.6 \%)$ & $10(11.7 \%)$ & $33(38.8 \%)$ & $33(38.8 \%)$ & $5(5.9 \%)$ \\
\hline Nac symmetry & $9(10.6 \%)$ & $27(31.8 \%)$ & $34(40 \%)$ & $15(17.6 \%)$ & $12(14.1 \%)$ & $30(35.3 \%)$ & $40(47.1 \%)$ & $3(3.5 \%)$ \\
\hline Breast shape & $29(34.1 \%)$ & $35(41.2 \%)$ & $15(17.6 \%)$ & $6(7.1 \%)$ & $31(36.5 \%)$ & $37(43.5 \%)$ & $9(10.6 \%)$ & $3(3.5 \%)$ \\
\hline Scarring & $20(23.5 \%)$ & $31(36.5 \%)$ & $28(32.9 \%)$ & $6(7.1 \%)$ & $22(25.9 \%)$ & $37(43.5 \%)$ & $23(27.1 \%)$ & $2(2.3 \%)$ \\
\hline Overall satisfaction & $32(36.6 \%)$ & $24(28.2 \%)$ & $23(27.1 \%)$ & $6(7.1 \%)$ & $35(41.2 \%)$ & $28(32.9 \%)$ & $17(20 \%)$ & $5(5.9 \%)$ \\
\hline
\end{tabular}

\section{Conclusions}

Breast Conserving Surgery (BCS) followed by radiotherapy has become the standard surgical approach for early stage breast cancer [12-15].

When adequate surgical margins are obtained local recurrence rates have been documented to range from 3.5 to $6.5 \%$ at 10 -year follow-up [16, 17]. The introduction of Oncoplastic Breast Surgery (OPBS) allowed wider local excisions avoiding breast distortions that usually follows resections larger than $10-15 \%$ of total breast volume [18] .

Upper-outer quadrantectomies can be easily performed with standard BCS but breast deformity and NAC displacement may follow this procedure. Different oncoplastic approaches have been proposed during the years trying to overcome these complications. Small-sized breasts with early breast cancer can be effectively treated by Benelli mastoplasty: glandular rotation flaps combine good cosmetic results with satisfactory resections [19]. When wider resections are required emi-batwing excisions or racquet mammoplasties have been successfully proposed $[20,21]$. These techniques consist in infero-medial flap reconstruction and supero-medial or inferior nipple repositioning with a skin resection of a crescent in combination with an ellipse. Although these techniques could achieve oncological radicality and good cosmetic results for the NAC position, the aesthetic result is affected by a long radial scar over the original tumor and a variable breast shape. Other authors propose the use of autologous tissue in order to fill the defect caused by upper-outer quadrantectomies. Even though flaps may provide pleasant aesthetic results, in our opinion these procedures should be reserved to selected cases because of their technical difficulty, their necessity of long operative time and issues related with donor site morbidity [22, 23]. Cutress proposed a modification of the Wise pattern reduction mammoplasty but using his technique the lower scar at the tumor side does not lie in the infra mammary fold but in the middle of the breast causing an important discomfort for the patient [24].

We aim to propose a reliable technique both respecting oncological radicality and preserving a pleasant breast contour. The large skin undermining and the breast reshaping performed using our technique do not determine NAC dislocations and irregular breast shapes.

Fitoussi and colleagues stated that the huge undermining could lead to increased rates of seroma, fat necrosis, bleeding and the NAC transposition may cause partial or total necrosis [25]. Other authors documented the relation between tumor location and the occurrence of complications. Tumors resection in the upper-outer quadrant tend to have higher complications rate when compared with other quadrants; the reason seems to be related with axillary lymphatics damage connected with tumor resection [26]. Our technique showed comparable short-term post-operative complication rates when compared with standard BCS and our rates are in line with those presented in literature.

Furthermore from an oncological point of view, we confirmed other data reported in literature evidencing that the oncoplastic approach reduces the number of re-operations for positive or close margins [27, 28].

We did not experience any delay for adjuvant therapies, either radio or chemotherapy, caused by a longer time of wound healing.

Some author suggest to postpone contra-lateral breast symmetrization after radiotherapy because of the risk of volume modification in the radiotreated breast [29]. We agree that fat necrosis or edema may derive from radiotherapy but we noted higher patients satisfaction levels 
when performing contra-lateral symmetrization in the same surgical time.

Our study presents the limitation of being retrospective and a longer follow-up could further confirm the oncological safety of the proposed surgical approach .

The proposed oncoplastic technique represents a safe and effective solution for reshaping that follows upper-outer breast cancer wide excision, achieving comparable complication rates, lower re-intervention rates for positive margins and better cosmetic results when compared with standard BCS.

\section{Abbreviations}

BCS: Breast conserving surgery; BMl: Body mass index; DCIS: Ductal carcinoma in situ; ER: Estrogen receptors; IDC: Invasice ductal carcinoma; MRI: Magnetic resonance imaging; NAC: Nipple areola complex OPBS: Oncoplastic breast surgery; PgR: Progesteron receptors; Tc99MAA: Technetium 99 macro albumin aggregated

\section{Acknowledgements}

Not applicable.

\section{Funding}

This manuscript did not receive sponsorship for publication.

\section{Availability of data and materials}

The datasets used and/or analysed during the current study are available from the corresponding author on reasonable request.

\section{About this supplement}

This article has been published as part of BMC surgery Volume 18 Supplement 1, 2018: Updates and New Technology in Endocrine Surgery. The full contents of the supplement are available online at https://bmcsurg.biomedcentral. com/articles/supplements/volume-18-supplement-1.

\section{Authors' contributions}

$D B, N R$ : conception and design, acquisition of the data, gave the final approval of the version to be published. NR, PC, MO, AG, SM, GF: drafted the manuscript, gave the final approval of the version to be published. AA, CM: critical revision, interpretation of data, gave the final approval of the version to be published. All the authors have read and approved the final manuscript.

\section{Ethics approval and consent to participate}

This study was approved by our institutional review board (Santa Maria della Misericordia Hospital Ethical Commitee \# 2014/8769) and appropriate informed consent was obtained from all patients for the surgical procedures performed in the present study and for personal images use and publication.

\section{Consent for publication}

The patients gave written, informed consent for publication.

\section{Competing interests}

The authors declare that they have no competing interests.

\section{Publisher's Note}

Springer Nature remains neutral with regard to jurisdictional claims in published maps and institutional affiliations.

\section{Author details}

'Department of Senology, Ospedale Santa Maria della Misericordia Urbino, Asur marche Area Vasta 1, Urbino, Italy. ${ }^{2}$ Plastic and Hand Surgery Unit, ASST San Gerardo, Monza, Italy. ${ }^{3}$ Department of Plastic Surgery, Marche Politechnic University, Ancona, Italy. ${ }^{4}$ Breast Surgery Unit, IRCCS-Arcispedale Santa Maria Nuova, Viale Risorgimento 80, 42123 Reggio Emilia, Italy. ${ }^{5}$ Department of Surgery, Breast Unit, University of Naples Federico II, Naples, Italy. ${ }^{6}$ Institute of Polymers, Composites and Biomaterials, National Research Council of Italy,
Viale J.F. Kennedy 54, Mostra d'Oltremare Pad. 20, 80125 Naples, Italy. ${ }^{7}$ Department of Industrial Engineering, Fraunhofer JL IDEAS, University of Naples Federico II, P.le Tecchio 80, 80125 Naples, Italy. ${ }^{8}$ Department of Clinical Medicine and Surgery, University of Naples "Federico II", Via S.Pansini, 5, 80131 Naples, Italy.

Received: 14 September 2018 Accepted: 29 December 2018

Published: 24 April 2019

\section{References}

1. Kronowitz SJ, Feledy JA, Hunt KK, et al. Determining the optimal approach to breast reconstruction after partial mastectomy. Plast Reconstr Surg. 2006; 117:1-11.

2. Baja AK, Kon PS, Oberg KC, Miles DA. Aesthetic outcomes in patients undergoing breast conservation therapy for the treatment of localized breast cancer. Plast Reconstr Surg. 2004;114:1442.

3. Jacobs L. Positive margins: the challenge continues for breast surgeons. Ann Surg Oncol. 2008;15:1271-2.

4. Morrow M, Hamilton AS, Katz SJ. Why do women get mastectomy? Results from a population-based study. J Clin Oncol. 2007;25:605.

5. Bordoni D, Cadenelli P, Rocco N, Ornelli M, Tessone A, Falco G, Magalotti C. Oncoplastic resection of breast cancers located in the upper-inner quadrants: a safe and effective surgical technique. Eur J Plast Surg. 2017. https://doi.org/10.1007/s00238-017-1340-9.

6. Baildam AD. Oncoplastic surgery of the breast. Br J Surg. 2002;89:532-3.

7. Rew DA. Towards a scientific basis for oncoplastic breast surgery. Eur I Surg Oncol. 2003;29:105-6.

8. Clough K, Lewis JS, Couturald B, Fitoussi A, Nos C, Falcou MC. Oncoplastic techniques allow extensive resections for breast conserving therapy of breast carcinomas. Ann Surg. 2003;237:26-34.

9. Veronesi U, Banfi A, Saccozzi R, et al. Conservative treatment of breast cancer. A trial in progress at the cancer institute of Milan. Cancer. 1977; 39(6):2822-6.

10. Veronesi U, Banfi A, del Vecchio M, et al. Comparison of Halsted mastectomy with quadrantectomy, axillary dissection, and radiotherapy in early breast cancer: long term results. Eur JCancer Clin Oncol. 1986;22:1085-9.

11. Zhu X, Egro FM, De La Cruz C. The "Wiser" oncoplastic reduction mammaplasty - An approach to challenging medial defects.Breast J. 2018; 24(6):1051-4.

12. Jacobson JA, Danforth DN, Cowan KH, d'Angelo T, Steinberg SM, Pierce L, et al. Ten-year results of a comparison of conservation with mastectomy in thetreatment of stage I and II breast cancer. N Engl JMed. 1995;332:907-11.

13. Fisher B, Dignam J, Wolmark N, Mamounas E, Costantino J, Poller W, et al. Lumpectomy and radiation therapy for the treatment of intraductal breast cancer:findings from National Surgical Adjuvant Breast and bowel project B17. J Clin Oncol. 1998;16:441-52.

14. Julien JP, Bijker N, Fentiman IS, Peterse JL, Delledonne V, Rouanet P, et al. Radiotherapy in breast-conserving treatment for ductal carcinoma in situ: first results of the EORTC randomised phase III trial 10853. EORTC Breast Cancer. Cooperative Group and EORTC Radiotherapy Group. Lancet. 2000; 355:528-33

15. Veronesi U, Cascinelli N, Mariani L, Greco M, Saccozzi R, Luini A, et al. Twenty-year follow-up of a randomized study comparing breast-conserving surgery with radicalmastectomy for early breast cancer. N Engl J Med. 2002; 347:1227-32.

16. Anderson SJ, Wapnir JJ, Dignam B. Prognosis after ipsilateral breast tumor recurrence and locoregional recurrences in patients. treated by breast-conserving therapy in five National SurgicalOS Reduces Mastectomy and Re-excision Adjuvant Breast and Bowel Projects protocols in node-negative Breast cancer. J Clin Oncol. 2009;29: 2466-73.

17. Scopa CD, Panagiotis AC, Tsamadas AC, Aletra C. Evaluation of margin status in lumpectomy specimens and residual breast carcinoma. Breast $\mathrm{J}$. 2006;12:150-3.

18. Cochrane RA, Valasiadou P, Wilson AR, Al-Ghazal SK, Macmillan RD. Cosmesis and satisfaction after breast-conserving surgery correlates with the percentage of breast volume excised. Br J Surg. 2003;90:1505-9.

19. Santanelli F, Paolini G, Campanale A, Longo B, Amanti C. Modified wisepattern reduction mammaplasty, a new tool for upper quadrantectomies: a preliminary report. Ann Surg Oncol. 2009;16(5):1122-7. 
20. Clough KB, Kaufman GJ, Nos C, Buccimazza I, Sarfati IM. Improving breast cancer surgery: a classification and quadrant per quadrant atlas for oncoplastic surgery. Ann Surg Oncol. 2010;17(5):1375-91.

21. Silverstein MJ, Mai T, Savalia N, Vaince F, Guerra L. Oncoplastic breast conservation surgery: the new paradigm. J Surg Oncol. 2014;110(1):82-9.

22. Dixon JM, Venizelos B, Chan P. Latissimus dorsi mini-flap: a technique for extending breast conservation. Breast. 2002 Feb;11(1):58-65.

23. Hamdi M, Van Landuyt $\mathrm{K}$, de Frene B, Roche N, Blondeel P, Monstrey S. The versatility of the inter-costal artery perforator (ICAP) flaps. J Plast Reconstr Aesthet Surg. 2006;59(6):644-52.

24. Cutress RI, Simoes T, Gill J, Hurren JS. Modification of the wise pattern breast reduction for oncological mammaplasty of upper outer and upper inner quadrant breast tumours: a technical note and case series. J Plast Reconstr Aesthet Surg. 2013;66(2):e31-6.

25. Fitoussi AD, Berry MG, Fama F, et al. Oncoplastic breast surgery for cancer: analysis of 540 consecutive cases. Plast Reconstr Surg. 2010;125(2):454-62.

26. Kronowitz SJ, Hunt KK, Kuerer HM, Strom EA, Buchholz TA, Ensor JE, Koutz CA, Robb GL. Practical guidelines for repair of partial mastectomy defects using the breast reductiontechnique in patients undergoing breast conservation therapy. Plast Reconstr Surg. 2007;120(7):1755-68.

27. Moran MS, Schnitt SJ, Giuliano AE, et al. Society of Surgical Oncology and American Society for Radiation Oncology consensus guideline on margins for breast-conserving surgery with whole-breast irradiation in stages I and || invasive breast cancer. J Clin Oncol. 2014;32(14):1507-15.

28. Morrow M. Breast conservation and negative margins: how much is enough? Breast. 2009;18:84-6.

29. Kronowitz SJ, Hunt KK, Kuerer HM, Strom EA, Buchholz TA, Ensor JE, Koutz CA, Robb GL. Practical Guidelines for Repair of Partial Mastectomy Defects Using the Breast Reduction Technique in Patients Undergoing Breast Conservation Therapy. Plast Reconstr Surg. 2007;120:1755.

Ready to submit your research? Choose BMC and benefit from:

- fast, convenient online submission

- thorough peer review by experienced researchers in your field

- rapid publication on acceptance

- support for research data, including large and complex data types

- gold Open Access which fosters wider collaboration and increased citations

- maximum visibility for your research: over $100 \mathrm{M}$ website views per year

At $\mathrm{BMC}$, research is always in progress.

Learn more biomedcentral.com/submissions 